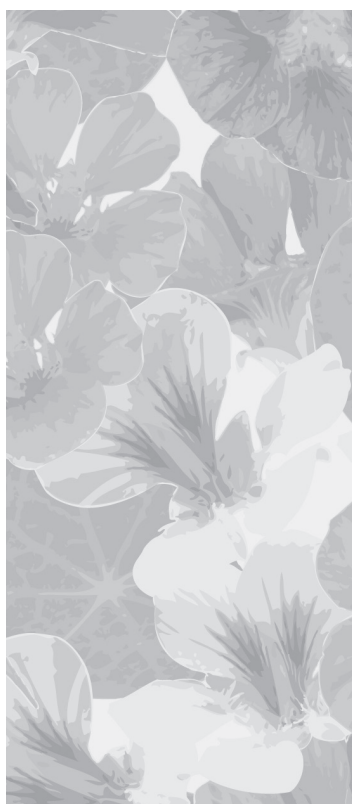

\title{
Częstość występowania skórnych reakcji niepożądanych na kosmetyki w miejscu pracy wśród pracowników salonów kosmetycznych
}

\author{
Prevalence of work-related adverse skin reactions to cosmetics \\ among employees of beauty salons
}

Radosław Śpiewak ${ }^{1,2}$, Agnieszka Doryńska ${ }^{3}$

${ }^{1}$ Zakład Dermatologii Doświadczalnej i Kosmetologii, Wydział Farmaceutyczny, Uniwersytet Jagielloński Collegium Medicum, Kraków

${ }^{2}$ Instytut Dermatologii, Kraków

${ }^{3}$ Zakład Epidemiologii i Badań Populacyjnych, Wydział Nauk o Zdrowiu, Uniwersytet Jagielloński

Collegium Medicum, Kraków

Estetol Med Kosmetol 2012; 2(2): 54-57

DOI: http://dx.doi.org/10.14320/EMK.2012.011

\section{Streszczenie}

Reakcje niepożądane na produkty kosmetyczne są częste w populacji generalnej. Nie ma natomiast danych na temat rozpowszechnienia tego typu problemów wśród personelu salonów kosmetycznych, który regularnie narażony jest na kosmetyki w środowisku pracy. Cel: Ocena częstości skórnych reakcji niepożądanych na kosmetyki w miejscu pracy wśród pracowników gabinetów kosmetycznych. Materiat i metody: Podczas kursów doksztatcających dla kosmetyczek i kosmetologów, zaprosiliśmy wszystkich uczestników pracujących w salonach kosmetycznych do udziału w anonimowych badaniach ankietowych. Badaną grupę stanowito 90 kobiet, mediana czasu zatrudnienia w salonie kosmetycznym wynosita 5 lat (zakres: od 1 miesiąca do 37 lat). Uczestniczki odpowiadały na pytanie, czy kiedykolwiek w życiu doświadczyły problemów skórnych, które wedtug nich były efektem niepożądanym kosmetyków. Następnie podawały typowe cechy takich problemów skórnych oraz odpowiadały na pytanie o pomoc lekarską, z jakiej korzystały w związku z wystąpieniem tych problemów. Wyniki: Dwadzieścia sześć uczestniczek (29\%) odpowiedziało, że doświadczyły problemów skórnych prowokowanych przez kosmetyki w miejscu pracy. U 18 z nich (69\%) problemy skórne ustąpiły po zaprzestaniu używania podejrzewanych kosmetyków. U 17 (65\%) powstawały one wyłącznie lub najczęściej w związku z wykonywanymi czynnościami zawodowymi. Opisane problemy skórne zmusity 19 respondentek (21\%) do skorzystania z pomocy lekarskiej, spośród nich 6 zostało skierowanych do lekarza medycyny pracy, a dalsze 4 otrzymały zalecenie zmiany pracy. Wnioski: Wśród pracowników salonów kosmetycznych co trzecia osoba odczuwa problemy skórne prowokowane przez produkty kosmetyczne, co piąta szuka z tego powodu pomocy lekarskiej, a u co dziesiątej lekarze podejrzewają chorobę zawodową.

Stowa kluczowe: problemy skórne prowokowane przez pracę, wyprysk zawodowy, świąd, kosmetolodzy, kosmetyczki

\section{Abstract}

Adverse skin reactions to cosmetic products are common among the general population. Little is known, however, about the prevalence of such problems among beauty salon employees who are constantly exposed to cosmetic products at their workplace. Aim: To assess the prevalence of adverse skin reactions to cosmetics in relation to work among the employees of beauty salons. Material and methods: A questionnaire-based study was conducted among 90 beauty salon workers during an educational course. All the respondents were women, with median employment duration of five years (range: 1 month to 37 years). Participants were asked about having ever in life any skin problems thought to be the adverse effects of cosmetics. They additionally answered questions about the nature of their skin problems, and the history of seeking medical help in relation to these problems. Results: Twenty-six participants (29\%) responded that they have experienced skin problems related to cosmetic products at their workplace. In this group, 18 (69\%) stated that their skin problems ceased after discontinuing use of the suspect cosmetics. Skin problems of 17 (65\%) were related exclusively or predominantly to their occupational activities. Medical help because of the skin problems was sought by 19 participants (21\%), of whom 6 were referred to an occupational physician, and another 4 were advised to change their occupation. Conclusion: One in three employees of beauty salons suffers from adverse skin reactions to cosmetic products, one in five seeks medical help because of these problems, while one in ten is suspected by a doctor of having an occupational disease.

Keywords: work-related skin problem, occupational dermatitis, pruritus, cosmetologists, beauticians

Copyright @ 2012 the Authors (text) and Radosław Śpiewak (layout \& journal compilation). All rights reserved.

W niedawnych badaniach duńskich $56,7 \%$ kobiet oraz 33,6\% mężczyzn podało, że przynajmniej raz w życiu doświadczyło działań niepożądanych po zastosowaniu kosmetyków [1]. Z racji wykonywanego zawodu pracownicy salonów kosmetycznych są znacznie bardziej narażeni na kosmetyki niż populacja generalna, jednak do tej pory nie prowadzono badań nad częstością występowania reakcji niepożądanych na kosmetyki w tej grupie zawodowej.

\section{Cel}

Celem niniejszej pracy była analiza częstości skórnych działań niepożądanych kosmetyków wśród pracowni- 
ków salonów kosmetycznych.

\section{Materiat i metody}

Badania wykonaliśmy przy okazji dwóch kursów „Problemy dermatologiczne spotykane w salonie kosmetycznym" zorganizowanych w latach 2009 i 2010 przez Instytut Dermatologii w Krakowie. Wszystkich uczestników tych kursów zaprosiliśmy do wypełnienia autorskiej ankiety. Aby uniknąć zasugerowania respondentów treściami przedstawianymi na kursie, ankieta została rozdana do wypełnienia przed rozpoczęciem kursu. Udział w opisanych badaniach był anonimowy i dobrowolny. Ankieta zawierała 11 pytań na temat działań niepożądanych kosmetyków. Pytania miały strukturę zamkniętą (możliwość zaznaczenia jednej lub kilku odpowiedzi) z miejscem na dodawanie własnych uwag lub obserwacji. Osoby, które doświadczyły działań niepożądanych kosmetyków, odpowiadały na szczegółowe pytania o typowe objawy, korzystanie z porad lekarskich w związku z opisanymi dolegliwościami, związek dolegliwości z wykonywaną pracą zawodową oraz ich wpływ na zdolność do pracy.

\section{Wyniki}

Uzyskaliśmy 90 kompletnie wypełnionych ankiet. W badaniu uczestniczyły same kobiety, staż pracy respondentek wynosił od 1 miesiąca do 37 lat (mediana 5 lat). W opinii zdecydowanej większości respondentek (93,3\%) problemy dotyczące negatywnych skutków stosowania kosmetyków są ważne społecznie i nie poświęca im się należytej uwagi. Zaledwie 12,2\% uczestniczek badania twierdziło, że nigdy nie zetknęły się z problemami skórnymi prowokowanymi przez kosmetyki lub inne substancje stosowane w salonach kosmetycznych (tab. 1). 26 respondentek (28,9\%) osobiście doświadczyło objawów niepożądanych po kosmetykach, w tym 19 (21,1\%) zwróciło się z tego powodu do lekarza (tab. 2). Jako lokalizację zmian skórnych prowokowanych przez kosmetyki w pracy, 16 respondentek (61,5\% zgłaszających takie problemy) wskazało na głowę (twarz, szyja), a następnie ręce (7 osób; 26,9\%) i przedramiona (3 osoby; 11,5\%). Respondentki, które łączyły w pracy obowiązki kosmetyczki i manicurzystki zgłaszały problemy skórne związane z używaniem kosmetyków w miejscu pracy częściej (38,5\%) niż ich koleżanki, które pracowały wyłącznie jako kosmetyczki (24,5\%). Zaobserwowana różnica nie była jednak istotna statystycznie.

\section{Dyskusja}

Składniki kosmetyków, takie jak konserwanty i substancje zapachowe należą do najczęstszych przyczyn alergii kontaktowej [2]. Spośród 113 polskich chorych na wyprysk testowanych ze składnikami kosmetyków, u 46 osób stwierdzono alergię na konserwanty, a u dalszych 3 na inne składniki [3]. Alergię na substancje zapachowe kosmetyków wykazuje 5-14\% chorych na wyprysk [4,5]. Uczulające składniki zawiera również zdecydowana większość emolientów - rozprowadzanych w aptekach kosmetyków przeznaczonych do pielęgnacji chorej skóry [6]. Również kosmetyki „naturalne” zawierają substancje o znanym potencjale uczulającym, np. Osmaron $B \circledR$ - naturalny konserwant pozyskiwany z ziaren palmy oleistej i oleju kukurydzianego. Częstość uczuleń na ten składnik wśród osób z przewlekłym wypryskiem szacuje się na 2\% [7]. Również inne składniki pochodzenia roślinnego - często reklamowane jako „naturalne i bezpieczne dla skóry” mogą być przyczyną alergii. Spośród 180 kosmetyków anti-aging do twarzy, składniki roślinne o znanym działaniu uczulającym występowały w 84 (47\%) produktach [8]. W związku z dużą liczbą składników wspólnych dla kosmetyków i przetworzonej żywności, alergia kontaktowa nabyta w warunkach zawodowych może następnie być podtrzymywana przez spożycie pokarmów (systemowy wyprysk alergiczny) [9].

Tabela 1. Odpowiedzi na pytanie „Czy kiedykolwiek spotkata się pani z problemami skórnymi związanymi z używaniem kosmetyków lub substancji stosowanych w salonach kosmetycznych i fryzjerskich?" (możliwość wyboru więcej niż jednej odpowiedzi)

\begin{tabular}{l|c|c}
\multicolumn{1}{c|}{ Odpowiedź } & $\mathbf{n}$ & $\mathbf{\%}$ \\
\hline Tak, takie problemy występowały/występują u mnie & 26 & 28,9 \\
\hline Tak, spotkałam/spotykam się z takimi problemami u klientów & 68 & 75,6 \\
\hline Tak, spotkałam się z takimi problemami u współpracowników & 7 & 7,8 \\
\hline $\begin{array}{l}\text { Nie, ale słyszałam od innych koleżanek "po fachu" } \\
\text { o występowaniu takich problemów }\end{array}$ & 16 & 17,8 \\
\hline Nie, nigdy nie spotkałam się z tego rodzaju problemami & 11 & 12,2 \\
\hline
\end{tabular}

Tabela 2. Charakterystyka działań niepożądanych kosmetyków oraz ich wpływu na funkcjonowanie zawodowe pracowników salonów kosmetycznych

\begin{tabular}{l|c|c}
\multicolumn{1}{c|}{ Opis problemu } & $\mathbf{n}$ & $\mathbf{\%}$ \\
\hline Problemy skórne prowokowane przez kontakt z kosmetykami: & $\mathbf{2 6}$ & $\mathbf{1 0 0 , 0}$ \\
\hline \multicolumn{1}{c|}{ świąd i widoczne zmiany skórne* } & 20 & 76,9 \\
\hline \multicolumn{1}{c|}{ świąd bez widocznych zmian skórnych* } & 8 & 30,8 \\
\hline $\begin{array}{l}\text { Problemy skórne ustappiły po zaprzestaniu stosowania } \\
\text { podejrzanych kosmetyków }\end{array}$ & 18 & 69,2 \\
\hline Problemy skórne pojawiały się wyłącznie w związku z pracą & 10 & 38,5 \\
\hline Problemy skórne pojawiały się głównie w związku z pracą & 7 & 26,9 \\
\hline Problemy skórne uniemożliwiają mi wykonywanie pracy & 2 & 7,7 \\
\hline Praca stała się bardziej uciążliwa (świąd, ból, dyskomfort) & 9 & 34,6 \\
\hline Klienci zauważają zmiany skórne i wyrażają negatywnie reakcje & 3 & 11,5 \\
\hline $\begin{array}{l}\text { Korzystalam z pomocy lekarskiej w związku opisanymi } \\
\text { problemami skórnymi, przy czym: }\end{array}$ & $\mathbf{1 9}$ & $\mathbf{1 0 0 , 0}$ \\
\hline $\begin{array}{l}\text { lekarz zasugerował badanie w kierunku choroby } \\
\text { zawodowej }\end{array}$ & 6 & 31,6 \\
\hline lekarz zalecił zmianę zawodu & 4 & 21,1 \\
\hline
\end{tabular}

*Niektóre respondentki zaznaczały obie odpowiedzi, co interpretujemy, że czasami odczuwały tylko świąd, a w innych przypadkach świądowi towarzyszyły widoczne zmiany skórne. 
Niezależnie od składników alergizujących, kosmetyki mogą zawierać substancje drażniące, których typowym przedstawicielem jest laurylosiarczan sodowy - popularny składnik kosmetyków, a zarazem modelowa substancja drażniąca w badaniach eksperymentalnych [10].

Kwestię chorób zawodowych w Polsce reguluje Kodeks pracy oraz Rozporządzenie Rady Ministrów w sprawie chorób zawodowych w aktualnie obowiązującym brzmieniu. Zgodnie z artykułem 235 kodeksu, za chorobę zawodową uważa się chorobę wymienioną w wykazie chorób zawodowych, jeżeli w wyniku oceny warunków pracy można stwierdzić bezspornie lub z wysokim prawdopodobieństwem, że została ona spowodowana działaniem czynników szkodliwych dla zdrowia występujących w środowisku pracy albo w związku ze sposobem wykonywania pracy (narażenie zawodowe). Rozpoznanie choroby zawodowej u pracownika lub byłego pracownika może nastąpić w okresie jego zatrudnienia w narażeniu zawodowym lub po zakończeniu pracy w takim narażeniu, pod warunkiem wystąpienia udokumentowanych objawów chorobowych w czasie ustalonym w wykazie chorób zawodowych [11]. W literaturze medycznej zaznacza się dotkliwy brak systematycznych lub przeglądowych opracowań na temat chorób skóry prowokowanych przez pracę w charakterze kosmetyczki lub kosmetologa. Rozdział poświęcony kosmetologom w najnowszym międzynarodowym podręczniku chorób zawodowych skóry Kanerva's Occupational Dermatology (2012) reprezentuje amerykańskie rozumienie tego zawodu i skupia się wyłącznie na środkach stosowanych w pielęgnacji i upiększaniu paznokci (paznokcie żelowe, sztuczne paznokcie), które głównie powodują zawodową alergię kontaktową na metakrylany [12]. W Europie większy nacisk w definiowaniu zakresu zawodu kosmetologa kładzie się na pielęgnację skóry niż na upiększanie paznokci [13], a doniesienia na temat chorób zawodowych powiązane z tymi aspektami zawodu ograniczają się do pojedynczych opisów przypadków. Jedno z nielicznych opublikowanych doniesień na ten temat pochodzi z Polski: w 2003 roku opisano przypadek zawodowego alergicznego wyprysku kontaktowego na kwiaty rumianku i limetki u kosmetyczki przygotowującej i aplikującej klientkom maseczki ziołowe [14]. Ponadto w literaturze można znaleźć doniesienie o irlandzkiej kosmetyczce, u której rozwinął się zawodowy alergiczny wyprysk kontaktowym na konserwant kosmetyków quaternium 15 oraz aplikowany przez nią u klientek wosk depilacyjny [15]. Wśród 99 pacjentów Instytutu Medycyny Pracy w Łodzi z podejrzeniem alergii kontaktowej na substancje zapachowe obecne w kosmetykach była zaledwie jedna osoba pracująca jako kosmetyczka [4]. Płynące $\mathrm{z}$ analizy literatury wrażenie pozornej rzadkości reakcji na kosmetyki u kosmetyczek i kosmetologów stoją w rażącym kontraście z wynikami naszych badań, w których na 90 badanych aż 10 osób podało, że w związku z ich dolegliwościami lekarze sugerowali przeprowadzenie badań w kierunku choroby zawodowej lub sugerowali zmianę zawodu, co również wskazuje na podejrzenie etiologii zawodowej problemów skórnych. Można na tej podstawie wysnuć przypuszczenie, że niewielka liczba opisywanych zawodowych chorób skóry prowokowanych przez kosmetyki w tej grupie zawodowej wynika nie tyle z rzadkości problemu, co z braku świadomości na temat chorób prowokowanych przez pracę w tej grupie zawodowej.

\section{Wnioski}

Wśród pracowników salonów kosmetycznych co trzecia osoba odczuwa problemy skórne prowokowane przez produkty kosmetyczne, co piąta szuka z tego powodu pomocy lekarskiej, a u co dziesiątej lekarze podejrzewają chorobę zawodową.

\section{Piśmiennictwo}

1. Thyssen JP, Linneberg A, Menne T, Nielsen NH, Johansen JD: The prevalence and morbidity of sensitization to fragrance mix I in the general population. Br J Dermatol 2009; 161(1):95-101.

2. Hamilton T, de Gannes GC: Allergic contact dermatitis to preservatives and fragrances in cosmetics. Skin Therapy Lett 2011;16(4):1-4.

3. Kieć-Świerczyńska M, Kręcisz B, Świerczyńska-Machura D: Uczulenie kontaktowe na środki konserwujące zawarte w kosmetykach. Med Pr 2006;57(3):245-9.

4. Kieć-Świerczyńska M, Kręcisz B, ŚwierczyńskaMachura D: Uczulenie kontaktowe na środki zapachowe. Med Pr 2006;57(5):431-7.

5. Gregorius A, Śpiewak R: Porównanie wyników testów płatkowych z zastosowaniem Europejskiej Serii Podstawowej, Polskiej Serii Podstawowej oraz rozszerzonej serii autorskiej w diagnostyce chorych z podejrzeniem alergii kontaktowej. Alergoprofil 2011;7(3):25-31.

6. Kordus K, Śpiewak R: Emolienty z apteki - pomoc czy zagrożenie dla chorych na wyprysk? Alergia Astma Immunol 2012;17(3):147-53.

7. Schnuch A: Osmaron B is a rare occupational, but a frequent cosmetic, allergen. Contact Dermatitis 2001;44(2):133-4.

8. Zabiegała A, Wojtanowska J, Śpiewak R: Występowanie składników roślinnych o znanym potencjale uczulającym w kosmetykach przeciwstarzeniowych. Pol J Cosmetol 2012;15(4):259-66.

9. Śpiewak R: Food-provoked eczema: A hypothesis on the possible role of systemic contact allergy to haptens present in both cosmetics and foods. Estetol Med Kosmetol 2011;1(1):35-40.

10. Basketter DA, Miettinen J, Lahti A: Acute irritant reactivity to sodium lauryl sulfate in atopics and nonatopics. Contact Dermatitis 1998;38:253-7.

11. Śpiewak R: Alergiczne choroby skóry związane z pracą zawodową. W: Fal AM (red). Alergia, choroby alergiczne, astma. Medycyna Praktyczna, Kraków 2011: 553-61. 
12. Engasser PG, Maibach HI, Tiet T, Taylor JS: Cosmetologists. W: Elsner P, John SM, Maibach HI, Rustemeyer T (red.). Kanerva's Occupational Dermatology. Springer, Heidelberg 2012: 1381-8.

13. Arct J: Kształcenie kosmetologiczne. Estetol Med Kosmetol 2012;2(1):7-10.

14. Rudzki E, Rapiejko P, Rebandel P: Occupational contact dermatitis, with asthma and rhinitis, from camomile in a cosmetician also with contact urticaria from both camomile and lime flowers. Contact Dermatitis 2003;49(3):162.

15. O'Reilly FM, Murphy GM: Occupational contact dermatitis in a beautician. Contact Dermatitis 1996;35(1):47-8.

\section{Finansowanie i konflikt interesów}

Przedstawione badania i przygotowanie niniejszej pracy zostało w całości sfinansowane $\mathrm{z}$ własnych środków autorów. Autorzy deklarują niewystępowanie konfliktu interesów w odniesieniu do treści zawartych w niniejszej pracy.

\section{Adres do korespondencji}

Radosław Śpiewak

Zakład Dermatologii Doświadczalnej i Kosmetologii

Wydział Farmaceutyczny UJ

ul. Medyczna 9, 30-688 Kraków

Tel.: 1262058 30, Fax: 126205645

E-mail: spiewak.eu@gmail.com

Data złożenia: 17.03 .2012

Data akceptacji: 21.06.2012

Data aktualizacji: 30.11 .2012

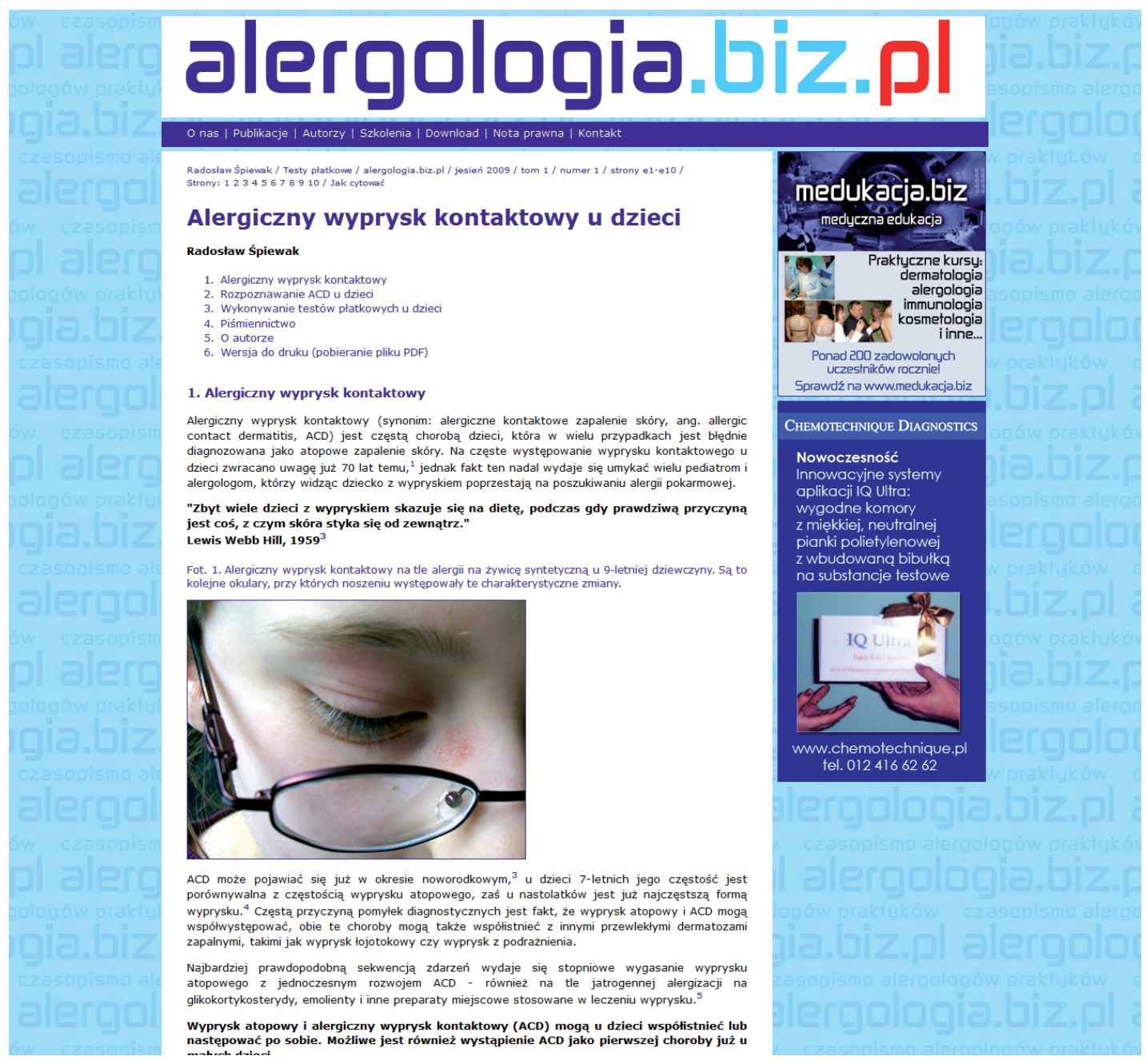

